\title{
Molecular characterization of multidrug-resistant Klebsiella pneumoniae and Escherichia coli harbouring extended spectrum beta-lactamases and carbapenemases genes at a tertiary hospital, Kenya
}

\author{
Daniel Maina, ${ }^{1}$ Gunturu Revathi, ${ }^{1}$ Andrew C. Whitelaw ${ }^{2}$ \\ ${ }^{1}$ Aga Khan University Hospital Nairobi, Kenya; ${ }^{2}$ National Health Laboratory Service, Tygerberg Hospital and Division \\ of Medical Microbiology, Stellenbosch University, Cape Town, South Africa
}

\section{Summary \\ Background. Multidrug-resistant (MDR) Gram negative rods are increasingly being reported in sub-Saharan Africa. Molecular investigations play an important role, alongside other measures, in controlling nosocomial infections attributed to these organisms.}

Correspondence: Maina Daniel, Aga Khan University Hospital Nairobi, P.O. Box 30270-00100, Nairobi, Kenya.

Tel.: +25.4720927338.

E-mail: daniel.maina@aku.edu

Key words: Molecular epidemiology; Antimicrobial resistance; Escherichia coli; Klebsiella pneumonia.

Contributions: DM conceived and designed the study, performed molecular studies and wrote the manuscript; GR processed the clinical specimens and carried out antimicrobial testing; ACW performed molecular studies and analysed the findings; GR and ACW reviewed and edited the manuscript.

Conflict of interest: the authors declare no potential conflict of interest.

Acknowledgements: the authors would thank the division of Microbiology, University of Cape Town and the Central analytic facility, Stellenbosch University in South Africa for the contributions made in the molecular investigations.

Funding: Funding was provided by Aga Khan University and University of Cape Town.

Conference presentation: paper partially presented at Regional Infection Prevention and Control (IPC) conference, Mombasa Kenya, November 2013.

Received for publication: 15 September 2017.

Revision received: 1 December 2017.

Accepted for publication: 5 December 2017.

CCopyright D. Maina et al., 2017

Licensee PAGEPress, Italy

Microbiologia Medica 2017; 32:7076

doi:10.4081/mm.2017.7076

This article is distributed under the terms of the Creative Commons Attribution Noncommercial License (by-nc 4.0) which permits any noncommercial use, distribution, and reproduction in any medium, provided the original author(s) and source are credited.
This study aimed to determine the common extended spectrum beta-lactamases (ESBL) and carbapenemases genes, and clonal relationship in MDR Klebsiella pneumoniae and Escherichia coli.

Methods. Fifty-four MDR isolates collected at the Aga Khan University hospital, Nairobi in the month of August 2012 formed the study. These were picked after an increase in the number of resistant strains during the said period was experienced.

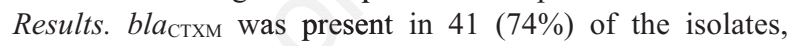
while bla $_{\mathrm{SHV}}$ was detected in $18(33 \%)$ and bla $a_{\mathrm{TEM}}$ in 13 (24\%) of the isolates.

Nine $(16.7 \%)$ of the isolates harboured all three ESBL genes and $8(14.8 \%)$ harboured two. Eight of the isolates (all E. coli) had none of the ESBL genes tested. Two isolates harboured carbapenemases genotypes: one had $b l a_{\mathrm{NDM}-1}$ and the other $b l a_{\mathrm{SPM}}$.

Sequencing matched CTXM-15 and TEM-1 genes in all the isolates harbouring $b l a_{\text {СтХм }}$ and $b l a_{\mathrm{TEM}}$ respectively. However, there was diversity in $b l a_{\mathrm{SHV}}$ with SHV-11 and SHV-12 genes predominant. The isolates were non-clonal.

Conclusions. The isolates mostly harboured $b l a_{\text {CTX-M-15 }}$ while only a few had carbapenemases genes. Lack of clonality suggests these were the stable circulating strains at the time of the study.

\section{Introduction}

The prevalence of antimicrobial resistance varies greatly between and within countries for different pathogens. Infections with multidrug-resistant (MDR) organisms have been linked with poorer clinical outcomes and prolonged hospitalization on average compared to infections with susceptible pathogens. This is likely exacerbated in resource-limited settings, where access to newer (usually more expensive) antibiotics is often limited by cost (27).

The factors that contribute to the emergence and spread of MDR microorganisms in developing countries are varied. These factors include inappropriate antimicrobial use by both medical personnel and the public, which is due to lack of prescribing skills or lack of access to microbiology laboratory reports (by the medical personnel), or due to unregulated access of patients to antibiotics in the retail market (28). Infection control practices within hospitals are in most places makeshift and often health care personnel may be unaware of emerging or existing multiresistant microorganisms due to lack of surveillance data coupled with inadequate microbiology laboratory facilities (15).

Extended spectrum beta-lactams and carbapenems are among the popular antimicrobials prescribed in severe infections. Therefore, antimicrobial resistance to these agents is of clinical 
and public health importance. ESBLs are beta lactamases capable of conferring bacterial resistance to the penicillins as well as first, second (but not the cephamycins) -, and third-generation cephalosporins, and aztreonam. On the other hand, carbapenemases are carbapenem-hydrolyzing beta-lactamases that confer resistance to a broad spectrum of beta-lactam substrates, including carbapenems. Recent studies performed in the region of East Africa show a wide variation in ESBLs prevalence in hospitals between the different countries with a pooled proportion of $40 \%$ reported in a meta-analysis (23). Carbapenemases have been documented in several countries in Africa and Rendani et al. in their systematic review have suggested that the problem might be bigger than what is currently estimated due to underreporting (11).

Molecular studies can be helpful in understanding the epidemiology of evolving and established MDR isolates in hospitals. Application of molecular techniques in infection control is gaining worldwide acceptance as the costs of carrying out the tests decrease; an example being whole genome sequencing which was employed to track an outbreak of a carbapenemase producing Klebsiella pneumoniae at a hospital in the USA (22). The Aga Khan University Hospital Nairobi (AKUHN) is a 250 bed tertiary and teaching hospital that caters mainly to the middle income population within the city, but also processes samples from across the country referred through its various outreach medical centres. The hospital runs an accredited microbiology laboratory.

Multidrug-resistant Enterobacteriaceae are often isolated in clinical specimens from both inpatients and outpatients at AKUHN. They are frequently implicated in infections involving the bloodstream, urinary tract, abdomen, skin and soft tissue. According to data on bloodstream infections (BSI) in the hospital from 2012 to 2014 only $30 \%$ of Klebsiella pneumoniae and $51 \%$ of Escherichia coli were susceptible to $3^{\text {rd }}$ generation cephalosporins, while $59 \%$ and $41 \%$, were susceptible to fluoroquinolones respectively (3).

Although some of the studies on antibiotic resistance in Gram negative rods conducted at this hospital have involved molecular techniques, few have addressed the issue of clonality among isolates within and between different locations in the hospital.

In the weeks leading to the month of August 2012 we noticed an increase in the number of MDR K. pneumoniae and E. coli and sought to determine the molecular mechanisms of resistance and clonality in these isolates at AKUHN.

\section{Materials and Methods}

In the month of August 2012 a total of $143 \mathrm{E}$. coli and $38 \mathrm{~K}$. pneumoniae isolates were cultured from clinical specimens in the microbiology laboratory. Among these, 35 (24\%) were MDR E. coli, and 19 (50\%) MDR K. pneumoniae respectively. The patients who provided the samples ranged from less than a month to 90 years in age with a median of 38 . There were more females (35) than males (19), which was attributed to a preponderance of UTIs in the females. Thirty of the isolates were from outpatients and 24 from inpatients. Multidrug-resistance was defined as non-susceptibility to one or more agents in three or more of the following antimicrobial agents: aminoglycosides, carbapenems, cephalosporins, fluoroquinolones, monobactams and penicillins.

Identification and susceptibility testing were performed using GNR and GN126 cards respectively on Vitek2 system (VITEK ${ }^{\circledR} 2$ bioMérieux, France). The Advanced Expert System (AES) on Vitek 2 configured the most likely phenotype for the majority of the isolates as extended spectrum beta-lactamase (ESBL). The Clinical
Laboratory and Standard Institutes (CLSI) guidelines for susceptibility breakpoints (version 2009) were used in this study.

\section{DNA extraction}

Fresh colonies were used for total bacterial DNA extraction using the ZR fungal/Bacterial DNA MiniPrep kit (Zymo Research Corp. USA) according to the manufacturer's protocol, with a final elution volume of $50 \mathrm{uL}$.

\section{PCR}

PCR for the common ESBL and carbapenemases genotypes bla $_{\mathrm{CTX}-\mathrm{M}} ; \quad$ bla $a_{\mathrm{SHV}} ; \quad$ bla $a_{\mathrm{TEM}} ;$ bla $_{\mathrm{KPC}}$, bla $a_{\mathrm{SPM}} ;$ bla $a_{\mathrm{GES}} ;$ bla $a_{\mathrm{IMP}} ;$ bla $a_{\mathrm{NDM}}$; $b l a_{\mathrm{OXA}}$; and bla $a_{\mathrm{VIM}}$ was performed using generic primers sourced from the University of Cape Town Oligonucleotide Synthesis Service (Table 1). Only isolates reported as non-susceptible to meropenem (MIC $\geq 4 \mathrm{ug} / \mathrm{mL}$ ) were tested for the presence of carbapenemase genes. For each target gene, PCR amplification was carried out in a $50 \mu \mathrm{L}$ reaction volume containing 1.25 units Taq DNA polymerase, $1.5 \mathrm{mM} \mathrm{MgCl}, 0.2 \mu \mathrm{M}$ of each of the forward and reverse primers, $200 \mu \mathrm{M}$ of each dNTP, $12.5 \mu \mathrm{L}$ of PCR water, and $2.5 \mu \mathrm{L}$ of DNA template.

The PCR amplicons were subjected to gel electrophoresis on PS $500 X$ (Hoefer Scientific instruments, USA) at $80 \mathrm{~V}$ for one hour, and then visualized using the Chemie Genius² Bio imaging system (Syngene, UK) after staining the gel with ethidium bromide.

\section{Sequencing}

The amplicons were sequenced using ABI3730xl (Life Technologies, USA) and the sequences assembled using the DNABaser software (Heracle BioSoft S.R.L, Romania). Sequences were compared to the published GenBank sequences using BLAST.

\section{Pulsed field gel electrophoresis (PFGE)}

PFGE was performed according to the PulseNet protocol for $E$. coli (www.cdc.gov/pulsenet/pdf/ecoli-shigella-pfge-protocol508.pdf) with modification-the restriction digestion time was extended to 3 hours at $37^{\circ} \mathrm{C}$. Only 16 of the E. coli and $15 \mathrm{~K}$. pneumoniae isolates were successfully typed.

The PFGE images were viewed in the Chemie Genius Bio imaging system (Syngene, UK) and analyzed using GelCompar software (Applied Maths, Belgium). Pulsotypes were derived by visualizing the bands and by computation based on the level of relatedness according to the DICE similarity coefficient and UPMGA. Optimization and tolerance limits were set at $1 \%$.

Isolates displaying $\geq 94 \%$ similarity $(\approx 3$ band difference) were assigned the same pulsotypes (26).

\section{Results}

The majority $(70 \%)$ of isolates were obtained from outpatient urine samples (Table 2). Other locations included the wards and critical care units that provided a variety of specimens. E. coli was mainly isolated in UTIs in outpatients while $K$. pneumoniae was associated with a variety of infections in inpatients.

The isolates were resistant to the majority of the 18 antibiotics tested against with the exception of meropenem and amikacin (Figure 1).

PCR for the ESBL genes showed that overall bla $a_{\text {СтXм }}$ was present in $41(74 \%)$ of the isolates, bla $a_{\mathrm{SHV}}$ in $18(33 \%)$ and $b l a_{\mathrm{TEM}}$ in $13(24 \%)$ (Table 2). There were notable differences between the two bacteria 
species in the proportion of isolates harbouring SHV; $E$. coli none, $K$. pneumoniae 18 (94.7\%), and TEM; E.coli 3 (8.6\%) and K. pneumoniae $10(52.6 \%)$. Sequence analysis showed that all CTX-M genes were $b l a_{\mathrm{CTX}-\mathrm{M}-15}$ and all TEM-related genes were $b l a_{\mathrm{TEM}-1}$. The predominant SHV-related genes were bla $_{\mathrm{SHV}-11}, 10(55.6 \%)$ and bla $_{\mathrm{SHV}-12}$ $6(33.3 \%)$. Others were $b l a_{\mathrm{SHV}-2}$ and $b l a_{\mathrm{SHV}-1}$ each present in a single isolate. bla $a_{\mathrm{SHV}}$ was exclusively found in K. pneumoniae while bla $a_{\mathrm{CTXM}}$ and $b l a_{\text {TEM }}$ were present in both of the microorganisms.

Nine $(16.7 \%)$ of the isolates harboured all three ESBL genes and 8 of the isolates (14.8\%) harboured two. Eight of the isolates (all E. coli) harboured none of the genes tested; all 8 of these isolates showed phenotypic resistance to $3^{\text {rd }}$ generation cephalosporins.

Only two isolates harboured carbapenemases genes: one had $b_{l} a_{\mathrm{NDM}-1}$ and the other bla $a_{\mathrm{SPM}}$; both were Klebsiella pneumoniae.

Molecular typing was performed in 16 of $E$. coli and 15 of $K$. pneumoniae isolates. Only two E. coli isolates (E4 and E20) belonged to the same pulsotype, while all of the $K$. pneumoniae isolates belonged to separate pulsotypes (Figures 2 and 3).

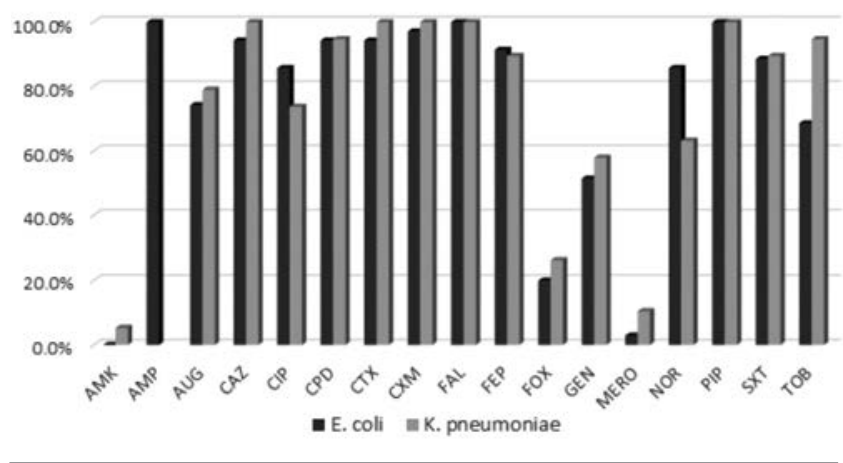

Figure 1. Proportion of isolates resistant to specific antibiotics $(\mathbf{n}=54)$. AMK amikacin; AMP ampicillin; AUG amoxil/clavulanate; CAZ ceftazidime; CIP ciprofloxacin; CPD cefpodoxime; CTX cefotaxime; CXM cefuroxime; FAL cefalotin; FEP cefepime; FOX cefoxitin; GEN gentamicin; MERO meropenem; NOR norfloxacin; PIP piperacillin; SXT sulfamethoxazole/trimethoprime; TOB tobramycin.

Table 1. Primers used for detection of resistance genes.

\begin{tabular}{|c|c|c|c|c|c|}
\hline Primer & & Primer sequence $\left(5^{\prime}-3^{\prime}\right)$ & Annealing temperature & Amplicon size (bp) & Reference \\
\hline SHV & $\begin{array}{l}\mathrm{F} \\
\mathrm{R}\end{array}$ & $\begin{array}{l}\text { CGC CGG GTT ATT CTT ATT TGT CGC } \\
\text { TCT TTC CGA TGC CGC CGC CAG TCA }\end{array}$ & $68^{\circ} \mathrm{C}$ & 1016 & (14) \\
\hline TEM & $\begin{array}{l}\mathrm{F} \\
\mathrm{R}\end{array}$ & $\begin{array}{l}\text { CTT CCT GTT TTT GCT CAC CCA } \\
\text { TAC GAT ACG GGA GGG CTT AC }\end{array}$ & $58^{\circ} \mathrm{C}$ & 717 & (3) \\
\hline CTX-M & $\begin{array}{l}\mathrm{F} \\
\mathrm{R}\end{array}$ & $\begin{array}{l}\text { TTT GCG ATG TGC AGT ACC AGT AA } \\
\text { CGA TAT CGT TGG TGG TGC CAT A }\end{array}$ & $51^{\circ} \mathrm{C}$ & 544 & (6) \\
\hline KPC & $\begin{array}{l}\mathrm{F} \\
\mathrm{R}\end{array}$ & $\begin{array}{l}\text { CGTCTAGTTCTGCTGTCTTG } \\
\text { CTTGTCATCCTTGTTAGGCG }\end{array}$ & $55^{\circ} \mathrm{C}$ & 798 & (19) \\
\hline SPM & $\begin{array}{l}\mathrm{F} \\
\mathrm{R}\end{array}$ & $\begin{array}{l}\text { CCTACAATCTAACGGCGACC } \\
\text { TCGCCGTGTCCAGGTATAAC }\end{array}$ & $55^{\circ} \mathrm{C}$ & 650 & (19) \\
\hline GES & $\begin{array}{l}\mathrm{F} \\
\mathrm{R}\end{array}$ & $\begin{array}{l}\text { CTATTACTGGCAGGGATCG } \\
\text { CCTCTCAATGGTGTGGGT }\end{array}$ & $55^{\circ} \mathrm{C}$ & 594 & (19) \\
\hline NDM & $\begin{array}{l}\mathrm{F} \\
\mathrm{R}\end{array}$ & $\begin{array}{l}\text { GGTTTGGCGATCTGGTTTTC } \\
\text { CGGAATGGCTCATCACGATC }\end{array}$ & $55^{\circ} \mathrm{C}$ & 621 & (19) \\
\hline VIM & $\begin{array}{l}\mathrm{F} \\
\mathrm{R}\end{array}$ & $\begin{array}{c}\text { GATGGTGTTTGGTCGCATA } \\
\text { CGAATGCGCAGCACCAG }\end{array}$ & $55^{\circ} \mathrm{C}$ & 390 & (19) \\
\hline OXA-48 & $\begin{array}{l}\mathrm{F} \\
\mathrm{R}\end{array}$ & $\begin{array}{l}\text { GCGTGGTTAAGGATGAACAC } \\
\text { CATCAAGTTCAACCCAACCG }\end{array}$ & $55^{\circ} \mathrm{C}$ & 438 & (19) \\
\hline IMP & $\begin{array}{l}\mathrm{F} \\
\mathrm{R}\end{array}$ & $\begin{array}{l}\text { GGAATAGAGTGGCTTAAYTC } \\
\text { TCGGTTTAAYAAAACAACCACC }\end{array}$ & $55^{\circ} \mathrm{C}$ & 232 & (19) \\
\hline
\end{tabular}

Table 2. Specimen type and resistance genes among the isolates.

\begin{tabular}{|c|c|c|}
\hline & $\begin{array}{l}E . \text { coli } \\
(\mathrm{n}=35)\end{array}$ & $\begin{array}{l}\text { K. pneumoniae } \\
(\mathrm{n}=19)\end{array}$ \\
\hline \multicolumn{3}{|l|}{ Specimen type: n (\%) } \\
\hline Urine & $28(80.0)$ & $10(52.6)$ \\
\hline Respiratory & $0(0)$ & $3(15.8)$ \\
\hline Pus / swabs & $3(8.6)$ & $2(10.5)$ \\
\hline Blood Culture & $3(8.6)$ & $2(10.5)$ \\
\hline Other & $1(2.9)$ & $2(10.5)$ \\
\hline \multicolumn{3}{|l|}{ Beta lactamase: n (\%) } \\
\hline bla-CTX-M & $26(74.3)$ & $15(78.9)$ \\
\hline bla-TEM & $3(8.6)$ & $10(52.6)$ \\
\hline bla-SHV & $0(0)$ & $18(94.7)$ \\
\hline
\end{tabular}




\section{Discussion}

We analyzed the molecular characteristics of multidrug resistant $K$. pneumoniae and E. coli isolates collected during one month at AKUHN to determine the common ESBL and carbapenemase genes, as well as to describe the clonal relationship of the isolates. The predominant genotype was bla $_{\mathrm{CTX- \textrm {M } - 1 5}}$ and was harboured by 41 $(74 \%)$ isolates. This finding was similar to that of an earlier study carried out in the hospital involving community acquired infections caused by the two organisms (10). The multidrug resistant isolates were present in all locations sampled in the hospital. Not surprisingly the majority of these isolates were implicated in urinary tract infections in the outpatient department. bla $_{\text {СТХ-М-15 }}$ has a worldwide presence and is one of the most common variants detected in clinically important pathogens, and predominates in most of Europe, North America, the Middle East and India $(8,29)$. Data from Africa seem to suggest it is also prevalent in this continent. A study in the neighboring Tanzania on ESBL producing $K$. pneumoniae found that among 92 isolates, 68 (74\%) had bla $a_{\text {СтХ-м-15 }}(13)$.
PFGE Xbal 2

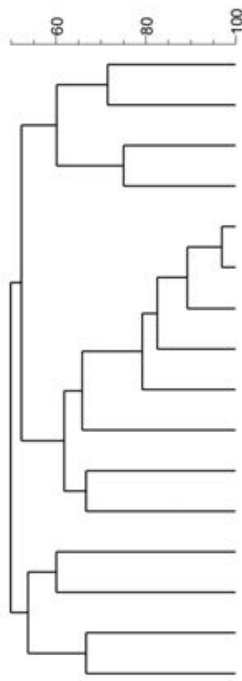

PFGE Xbal 2

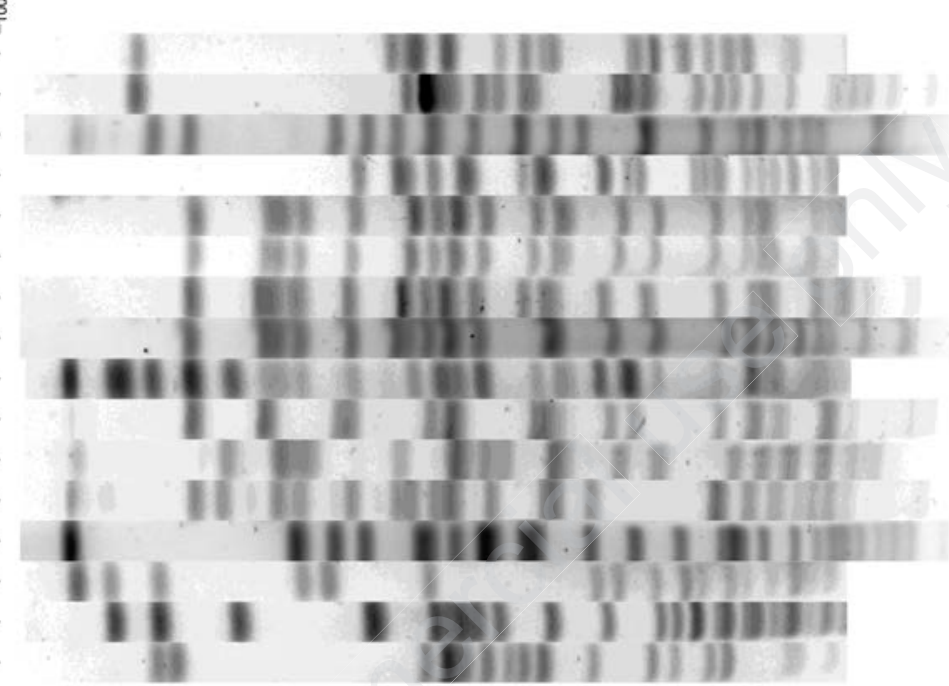

E19 HDU

E2 ICU

E10 Outpatient

E14 Outpatient dept

E20 Outpatient dept

E4 Outpatient dept

E5 Outpatient dept

E1 Outpatient dept

E24 Paediatric ward

E9 Outpatient dept

E11 Outpatient

E6 Outpatient dept

E3 Outpatient dept

E34 Private ward

E30 Outpatient dept

E33 Outpatient

Figure 2. PFGE $E$. coli. HDU- high dependence unit; ICU- intensive care unit.

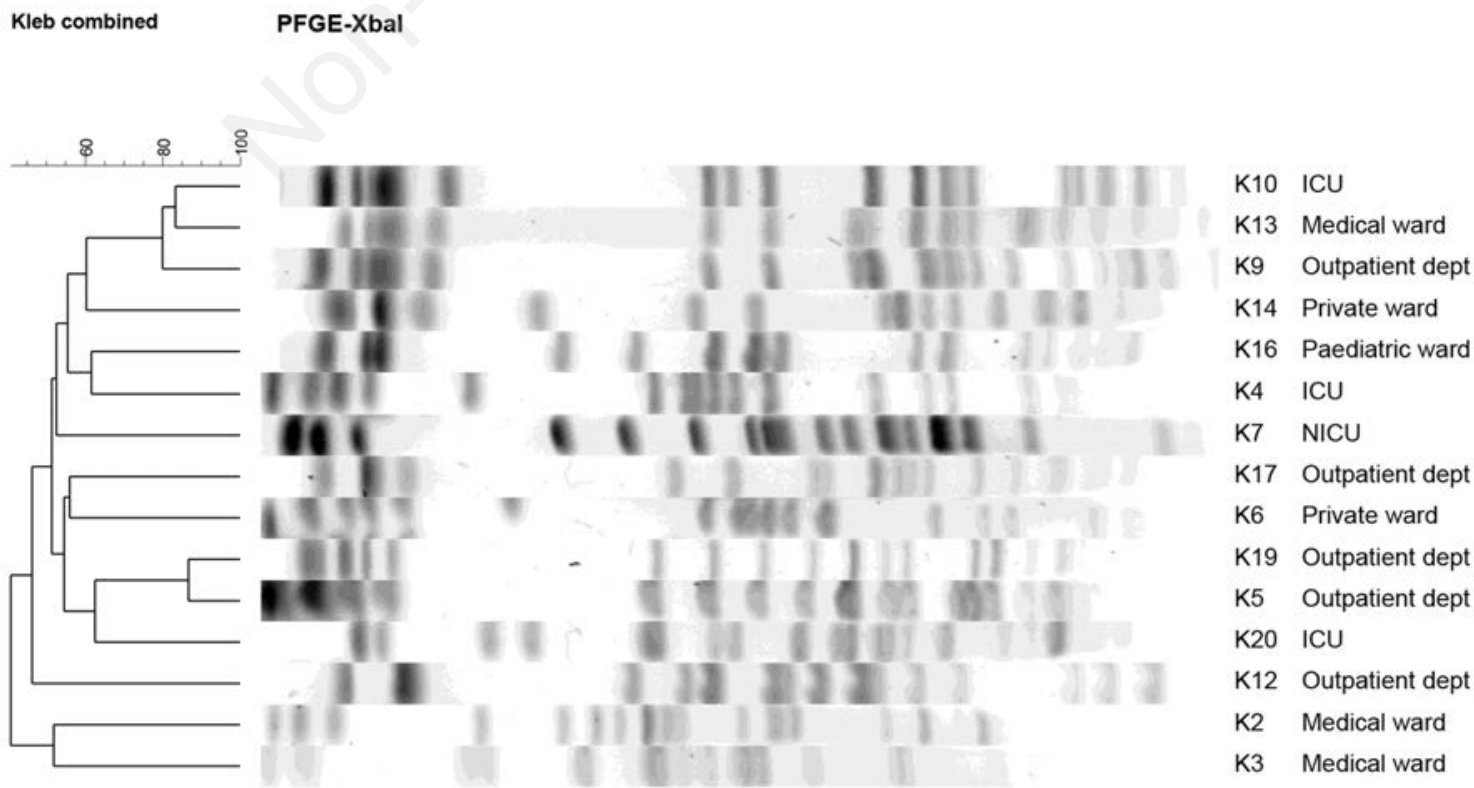

Figure 3. PFGE K. pneumoniae. HDU; high dependence unit; ICU- intensive care unit; NICU-neonatal intensive care unit. 
Presence of the genotype $b l a_{\mathrm{CTX}-\mathrm{M}-15}$ has also been reported in other countries including Morocco, Tunisia, Algeria, Egypt, Nigeria and South Africa $(16,25)$. Apart from humans the environment as well as animals that are a food source serve as reservoirs for ESBLs and studies done on different continents have documented evidence, which in part explains the global presence and spread of ESBLs $(1,2,12)$.

Eight of the isolates with phenotypic resistance to $3^{\text {rd }}$ generation cephalosporins did not harbour any of the common ESBL genes tested. It is possible that other mechanisms of resistance, besides beta-lactamases, or other beta-lactamases whose genes were not tested for could be involved. One possible mechanism is the presence of AmpC beta-lactamases; however this seems unlikely considering that among the eight isolates only one was resistant to cefoxitin. Another plausible explanation is the presence of false positive ESBL phenotypes as determined by the automated system (Vitek2) since it is not $100 \%$ specific for ESBLs. Specificity varies between studies with some reporting above $97 \%$ $(21,24)$ while others report values lower than $90 \%(4,7)$. In our study, confirmatory tests for ESBL production for the eight isolates were not were not performed.

Only 2 isolates, both Klebsiella, were found to harbour carbapenemases genes i.e. bla $a_{\mathrm{NDM}-1}$ and bla $a_{\mathrm{SPM}}$.

$b l a_{\mathrm{NDM}-1}$ which gained prominence in the last decade had been described in K. pneumoniae isolates dating back to 2007 in this hospital and later was also isolated in Acinetobacter baumanii $(18,20)$. However, carbapenemases producing K. pneumoniae and $E$. coli have remained relatively uncommon compared to ESBLs in Kenya. A systematic review that analysed carbapenemase-producing bacteria in Africa found diverse prevalence among hospital isolates ranging from to $2.3 \%$ to $67.7 \%$. The review concluded that antibiotic stewardship and surveillance systems, including molecular typing of resistant isolates, should be implemented to control the spread of carbapenemase-producing bacteria (11).

The SPM- type carbapenemase is a metallo-beta-lactamase (MBL) that is reported mostly in South America among Pseudomonas aeruginosa ( $P$. aeruginosa) and Acinetobacter baumanii (A. baumanii). There are limited data on the prevalence of the SPM-type carbapenemase in Africa. A study conducted in Uganda showed that $16 \%(4 / 25)$ of carbapenem-resistant $P$. aeruginosa harboured bla $a_{\mathrm{SPM}}(5)$.

Although only a limited number of isolates were analysed by PFGE, results show the existence of different pulsotypes among the two species within the various hospital locations and makes clonal spread of the MDR isolates less likely. However, these studies need to be repeated to involve larger numbers of isolates collected over a longer time span to better understand the emergence and spread of the resistant isolates. Molecular investigations integrated with conventional hospital epidemiologic surveillance can be cost effective in reducing nosocomial infections (17). Clonality can be used to track the source and spread of an infection and a relapse from a re-infection. These information can lead to targeted infection control measures. However, the resources required to perform molecular studies are prohibitive in under-resourced countries- a situation that prevails in most of Africa.

The research reported here had limitations including low number of isolates typed and limited time of the study. However, we believe it provides a snapshot of what was happening in the hospital at the time, and can be used to assist future studies. Most importantly, it suggests that clonal dissemination of these resistant isolates is unlikely.

\section{Conclusions}

MDR E. coli and K. pneumoniae mostly harboured bla $a_{\mathrm{CTX}-\mathrm{M}-15 \text {, }}$ and carbapenemases were uncommon. Among the isolates that underwent molecular typing no clonality was demonstrated suggesting they arose by means other than clonal spread, and were probably the stable circulating strains at the time of the study.

\section{References}

1. Ali T, ur Rahman S, Zhang L, et al. ESBL-Producing Escherichia coli from Cows Suffering Mastitis in China Contain Clinical Class 1 Integrons with CTX-M Linked to ISCR1. Front Microbiol 2016;7.

2. Chishimba K, Hang'ombe B, Muzandu K, et al. Detection of Extended-Spectrum Beta-Lactamase-Producing Escherichia coli in Market-Ready Chickens in Zambia. Int J Microbiol 2016;2016.

3. Edelstein M, Pimkin M, Palagin I, et al. Prevalence and molecular epidemiology of CTX-M extended-spectrum $\beta$-lactamaseproducing Escherichia coli and Klebsiella pneumoniae in Russian hospitals. Antimicrob Agents Chemother 2003;47: 3724-32.

4. Färber J, Moder KA, Layer F, et al. Extended-spectrum betalactamase detection with different panels for automated susceptibility testing and with a chromogenic medium. J Clin Microbiol 2008;46:3721-7.

5. Kateete DP, Nakanjako R, Namugenyi J, et al. Carbapenem resistant Pseudomonas aeruginosa and Acinetobacter baumannii at Mulago Hospital in Kampala, Uganda (2007-2009). SpringerPlus. 2016;5:1308.

6. Lal P, Kapil A, Das BK, et al. Occurrence of TEM \& SHV gene in extended spectrum [beta]-lactamases (ESBLs) producing Klebsiella sp. isolated from a tertiary care hospital. Indian J Med Res 2007;125:173.

7. Leverstein-van Hall MA, Fluit AC, Paauw A, et al. Evaluation of the Etest ESBL and the BD Phoenix, VITEK 1, and VITEK 2 automated instruments for detection of extended-spectrum beta-lactamases in multiresistant Escherichia coli and Klebsiella spp. J Clin Microbiol 2002;40:3703-11.

8. Livermore DM. Current epidemiology and growing resistance of gram-negative pathogens. Korean J Intern Med 2012;27: 128-42.

9. Maina D, Omuse G, Revathi G, et al. Spectrum of microbial diseases and resistance patterns at a private teaching hospital in Kenya: implications for clinical practice. PLoS One 2016;11.

10. Maina D, Revathi G, Kariuki S, et al. Genotypes and cephalosporin susceptibility in extended-spectrum beta-lactamase producing enterobacteriaceae in the community. J Infect Dev Countr 2011;6:470-7.

11. Manenzhe RI, Zar HJ, Nicol MP, et al. The spread of carbapenemase-producing bacteria in Africa: a systematic review. J Antimicrob Chemother 2014;70:23-40.

12. Moremi N, Manda EV, Falgenhauer L, et al. Predominance of CTX-M-15 among ESBL producers from environment and fish gut from the shores of Lake Victoria in Mwanza, Tanzania. Front Microbiol 2016;7.

13. Mshana SE, Hain T, Domann E, et al. Predominance of Klebsiella pneumoniae ST14 carrying CTX-M-15 causing neonatal sepsis in Tanzania. BMC Infect Dis 2013;13:1.

14. Nüesch-Inderbinen $M$, Hächler H, Kayser F. Detection of 
genes coding for extended-spectrum SHV beta-lactamases in clinical isolates by a molecular genetic method, and comparison with the E test. Eur J Clin Microbiol Infect Dis 1996;15: 398-402.

15. Okeke IN, Lamikanra A, Edelman R. Socioeconomic and behavioral factors leading to acquired bacterial resistance to antibiotics in developing countries. Emerg Infect Dis 1999; $5: 18$.

16. Peirano G, van Greune CH, Pitout JD. Characteristics of infections caused by extended-spectrum $\beta$-lactamase-producing Escherichia coli from community hospitals in South Africa. Diagn Microbiol Infect Dis 2011;69:449-53.

17. Peterson LR, Noskin GA. New technology for detecting multidrug-resistant pathogens in the clinical microbiology laboratory. Emerg Infect Dis 2001;7:306.

18. Poirel L, Revathi G, Bernabeu S, et al. Detection of NDM-1producing Klebsiella pneumoniae in Kenya. Antimicrob Agents Chemother 2011;55:934-6.

19. Poirel L, Walsh TR, Cuvillier V, et al. Multiplex PCR for detection of acquired carbapenemase genes. Diagn Microbiol Infect Dis 2011;70:119-23.

20. Revathi G, Siu LK, Lu P-L, et al. First report of NDM-1-producing Acinetobacter baumannii in East Africa. Int J Infect Dis 2013;17:e1255-8.

21. Singh RM, Singh HL. Comparative evaluation of six phenotypic methods for detecting extended-spectrum beta-lactamase-producing Enterobacteriaceae. J Infect Dev Countr 2014;8:408-15.

22. Snitkin ES, Zelazny AM, Thomas PJ, et al. Tracking a hospital outbreak of carbapenem-resistant Klebsiella pneumoniae with whole-genome sequencing. Sci Transl Med 2012;4:148ra16.

23. Sonda T, Kumburu H, van Zwetselaar M, et al. Meta-analysis of proportion estimates of Extended-Spectrum-BetaLactamase-producing Enterobacteriaceae in East Africa hospitals. Antimicrob Resist Int 2016;5:1.

24. Spanu T, Sanguinetti M, Tumbarello M, et al. Evaluation of the new VITEK 2 extended-spectrum beta-lactamase (ESBL) test for rapid detection of ESBL production in Enterobacteriaceae isolates. J Clin Microbiol 2006;44:3257-62.

25. Storberg V. ESBL-producing Enterobacteriaceae in Africa: a non-systematic literature review of research published 20082012. Infect Ecol Epidemiol 2014;4:20342.

26. Tenover FC, Arbeit RD, Goering RV, et al. Interpreting chromosomal DNA restriction patterns produced by pulsed-field gel electrophoresis: criteria for bacterial strain typing. J Clin Microbiol 1995;33:2233.

27. Vila J, Pal T. Update on antibacterial resistance in low-income countries: factors favoring the emergence of resistance. Open Infect Dis J 2010;4:38-54.

28. Wolff MJ. Use and misuse of antibiotics in Latin America. Clin Infect Dis 1993;17:S346-S51.

29. Zhao WH, Hu ZQ. Epidemiology and genetics of CTX-M extended-spectrum $\beta$-lactamases in Gram-negative bacteria. Crit Rev Microbiol 2013;39:79-101. 